\title{
Environmental Management System in Modern Russia: Problems, Analysis and Ways of Enhancement
}

\author{
Nadezhda Arkhipova \\ Department of Organizational Development \\ Russian State University for the Humanities \\ Moscow, Russia \\ E-mail: prorektor207@gmail.com
}

\author{
Valeriy Nezamaikin \\ Department of Finance and Credit \\ Russian State University for the Humanities \\ Moscow, Russia \\ E-mail: nezamaikinvn@mail.ru
}

\author{
Vitaliy Umnov \\ Faculty of Economics \\ Russian State University for the Humanities \\ Moscow, Russia \\ E-mail: umnov.v@rggu.ru
}

\begin{abstract}
The article analyses existing problems of environmental management that demand international approach to their solving. It is proposed to take into consideration Russia's specific characteristics in terms of environmental and economic conditions. The authors study international and Russian experience of environmental management aimed at sustainable development and symbiosis of society and natural environment. The authors carried out the Cobb-Douglas analysis of Russian problems in the sphere of the natural resources use. The paper suggests an approach to the environmental management on the basis of natural complexes consideration.
\end{abstract}

Keywords-environmental management; environmental protection; natural resources use usage management system; sustainable development; natural resources

\section{INTRODUCTION}

Natural resources have always been and will be one of the most important factors that provide for the existence of human society. At the early stages of their development humans existed in complete harmony with the environment being its integral part. However, the progress, one of the characteristic features of social development, increasingly separated society thus transforming nature into a consumable. The importance of reasonable and rational consumption of natural resources has significantly increased in the past decades when the natural capacities of the biosphere became incapable of satisfying the ever-rising demands of the society.

At present, we witness an increasing number of ecological catastrophes, of injurious disposition of the natural resources connected with obtaining short-term economic profits instead of long-term social advantages. The humanity has to be aware of the fact that the biosphere belongs not only to the living but also to the future generations and our top priority aim is to preserve the natural resources as fully as we can. Consequently, we can assume that the world community is now facing the problem of reasonable and rational natural resources management [1].

\section{THE MAJOR TRENDS IN ENVIRONMENTAL MANAGEMENT IN THE WORLD}

It is quite understandable that active organizational and coordinating efforts are being undertaken on the international level in order to create a joint worldwide strategy of rational natural resources usage. The world community has developed common provisions of the sustainable development concept, several proposals on lowering consumption of natural resources and pollution have been made, inter-government program documents have been developed, and their provisions are supposed to form the basis of national strategies of natural resources consumption [2].

The international character of the consequences of ecological catastrophes and irrational environment management has become a serious incentive to activate the environment-preserving activities. Local ecological catastrophes caused by the current level of technogenic development quite frequently affect the neighboring countries. Today we are facing not only economic but also ecological and natural resources globalization that must increasingly effect the creation of national socio-economic development strategy and tactics in any country or region. 


\section{CURRENT RUSSIAN PROBLEMS IN NATURAL RESOURCES MANAGEMENT}

We need to admit that the problem of rational natural resources management is very relevant for the Russian Federation as well. It is generally known, that Russia is one of countries that are the richest in natural resources - in terms of their quantity as well as in terms of their diversity. This wealth along with a whole series of political and economic characteristics of development of the country in the XX and XXI centuries created in our society an exclusively consumerist attitude to the environment, and also favored formation of the resource-oriented national economy. Until present the sectors of economy that are based on inefficient and wasteful exploitation of natural resources play the dominant part in national economy. The authors believe that the main problem that prevents efficient usage of natural resources complex of Russia is the lack of a scientifically proven system of environmental management which has to meet the following obligatory criteria: It should

- Be based on the system of strategic targets of socioeconomic and ecological development of the country or region which will be set by the legislative and executive power authorities on corresponding levels;

- Have a strictly determined object and subject of management;

- Have a complete and high-quality information basis of management which will permit to make rational human resources management decisions;

- Have an adequate system of evaluation of possible outcomes of the decisions taken within the framework of this system which will permit to evaluate economic efficiency of the environmental management system on various stages of decisionmaking;

- Have a clear vertical and horizontal division of powers and responsibility between various levels of environmental management [3].

We consider the development of a management system in accordance with the above requirements to be a relevant scientific problem that demands prompt solution. We have to begin with mentioning that contemporary usage of natural resources (and of course environmental management) is positioned within rigid framework that considerably diminishes the level of freedom of subjecs of environmental management. We mean here the limitations of natural resources. It is a well-known fact that current capacities of the biosphere are incapable of fulfilling the current level of needs of the human society. In this respect the world society has developed several humanitarian concepts aimed at establishing possible ways of co-existence of society and natural environment. The principle of sustainable development is the central part of these concepts approved worldwide.

Due to circumstances of economic and socio - political nature, the Russian economy is currently a consumer of natural resources and this consumption's levels are increasing at a substantial rate. Therefore the current status of relationship between the nature and the society in Russia can be described as simple exploitation of natural resources thus contradicting one of the fundamental principles of sustainable development, i.e. mutually beneficial coexistence of the human society and natural environment. Meanwhile the modern state doctrine of sustainable development of the Russian Federation is purely declaratory. At present, there is neither a system of measures to support the principles of the concept nor any mechanisms of coordinating the conditions and restrictions of sustainable development with the reality of economic relations.

\section{CONCEPT OF ENVIRONMENT MANAGEMENT SYSTEM IN RUSSIA}

In order to increase the illustration of comparative-logical analysis we use such well- known economic instrument as the Cobb-Douglas function. Traditionally this instrument is used in macroeconomic analysis which is an additional argument in its favor. Due to their social value the natural resources should not be described in the framework of microeconomics (as it is done traditionally, for example, in economics textbooks whereby the natural resources markets in general and the land market in particular are studied in the Microeconomics part) but should be discussed on the macro level. Therefore, the application of the Cobb-Douglas function in this particular case will lead in our opinion to the increasingly adequate results of analysis.

The main result of the comparative-logical analysis is the comprehension of the fact that in the present circumstances none of the unipolar approaches to the problem of the joint development of the society and the environment (i.e. approaches in which the central role is given either to the man, or to the environment) provides for the social and economic development of the society in the circumstances where the restrictions of the sustainable development have to be applied.

Therefore, by method of exclusion, the only acceptable concept of co-existence of the society and the biosphere is the "bipolar" noospheric approach. However, this approach requires transformation of social conscience and does not lie in the sphere of economic or political-economic relations (as anthropocentric or ecocentric approaches). It is primarily in the sphere of social relations. We must note that the said transformation of social conscience that can be considered as formation of "ecological thinking" has been continuously and successfully carried out in economically developed countries. Similar attempts are undertaken on the level of state associations, however in this case their efficiency is substantially lower due to objective circumstances. We will discuss these circumstances in more detail as not only do they influence success of this transformation on the level of world community but they basically determine perspectives of this process in Russia.

We deal here with prioritizing various needs of a man. As proven by sociologists and economists, the levels of importance for both a single person and a society as a whole are established starting from physiological needs (highest 
priority) to the need of spiritual self-development (lowest priority). The satisfaction of the next level starts only after the needs of higher priority have been satisfied. Obviously, the "ecological thinking" as such should be considered as spiritual self-development, i.e. low-priority need. In reality it means that the mankind will start applying "ecological thinking" notions only after all of its higher priority needs are satisfied. These needs include higher quality of life for all of the mankind, economic guarantees of future wellbeing etc. We can logically suppose that the economic base for such a quality social leap will be built in distant future, probably much later than all of the natural resources are destroyed in the name of building this base. Meanwhile, until this base is built the humanity will view the environment not from social but from economic positions [4].

However, the need of strategic transition to "ecological thinking" (provided complete preservation of natural resources is reached) leads to the next important requirement for the system's functioning: the evaluation of any decision taken in the framework of environmental management system should be carried out not only from the standpoint of economic efficiency of its realization but from the standpoint of the social effect which will make it clear to what extent the decision corresponds to the strategic aim of formation of "ecological thinking". The process of formation of "ecological thinking" is successfully occurring in certain economically developed countries today. This process has several specific characteristics. It's obvious that even today we can see some countries where the standards of live and the level of social and economic development are so high that it gives these countries the opportunity to reach the level of "ecological thinking". In our opinion, the countries of Northern Europe (for example Iceland, Sweden, Norway) can be included in this list. Severe weather and climate conditions, as well as other conditions of cultural and economic nature formed the base for the creation in these (and some other countries) of a cultural tradition of coexistence of a human being and environment as two equal individuals. And the relatively small scale of national economies and population numbers contributed to the creation on this cultural-historic base of the highlydeveloped industrial economy with ecological orientation (as in Sweden) or of the post-industrial economy (as in Iceland).

However, presently very few countries have the capabilities needed for this type of development. Consequently, another direction of "ecological thinking" formation - or, to be more precise - of formation of conditions for co-existence of society and environment corresponding to such thinking has emerged in the last decades. We need to note that this direction differs from the "pure ecological thinking" seen in the Northern European countries and can be described as "selective ecological thinking" that can be characterized as "double standards policy". The essence of this direction lies in different attitude of the government and the people to the environment of their own country and of the other countries. While the concept of "ecological thinking" is applied to a certain extent to their own (national) environment, the followers of this direction apply ordinary consumerist approach to the natural resources of other countries. In other words the world community is divided into countries-donors and countries-recipients of natural resources. Practical realization of this "double standards" policy in respect to the environment served as a pre-requisite for the appearance of the idea of globalization as one of the main contemporary ideas of the co-existence of the world community [5].

The authors consider a detailed study of economic consequences of globalization to be extremely important from the standpoint of analysis of potential effects these processes can have on natural resources. A special importance is attributed to the process of national economies' specialization as a direct consequence of globalization.

Considering the extreme importance of a national concept of nature usage as well as all the existing difficulties in its formation and practical realization under the influence of globalization processes, one can determine a series of requirements that have to be taken into consideration during the process of development of national and regional strategy of natural resources potential usage.

\section{THE APPROACH TO NATURE USAGE ON THE BASIS OF THE COMPLEXITY OF NATURAL OBJECTS}

All of the above will permit us to draw the following important conclusion: in the current circumstances one of the functions of management acquires extreme importance and this function is planning the essence of which is managing the future state of the object of management. Goal-setting is an integral part of planning, and so is plans realization control (or monitoring). Taking into consideration the complexity of practical realization of the control function, on the one hand, and the extreme importance of this function in the present conditions (in the present situation the effective natural resources management system has no margin for error) it is necessary to put the main efforts in the sphere of control into pre-active evaluation or a priori control.

An integral part of realization of the planning function with regard to limited resources (including natural resources) is constituted by the problems of allocation or distribution of these resources.

In this respect it is necessary to note that while the study of territorial and space allocation problems lies within the framework of economic relations, the consideration of institutional (beneficiary) allocation leads to necessity of a detailed analysis of legal questions including the problem of property rights distribution.

We need to note that in spite of the fact that the study of allocation problems will be completed in the economicallegal aspect, its final results (in accordance to the above) will be completely economic. Due to the importance of this problem the authors decided to pay specific attention and discuss it in a separate article.

The authors presume that for the solution of various management problems any natural resource should be considered as a complex or a system named "the complex of 
the natural resource". In its simplest option the complex will contain two components: the resource itself (not the land, but water or forest resource) and the plot of land on which it is located.

The economic effect of this complex of natural resource will be primarily connected with the possibility of diversification of the possibilities of complex usage as compared to the possibilities of resource usage. For example, if there can be only two options of managerial decision with regard to coal (extract or permit extraction) or do not extract, the possibilities can be widely broadened by involving the plot of land - for example, instead of coal extraction the decision can be taken to permit construction of a large recreational complex of inter-regional importance capable of generating more revenue than a coal mine could.

\section{CONCLUSION}

Global ecological problems that are increasingly present today demand joint measures for their solution on the worldwide scale. Meanwhile Russian environmental management has its specific characteristics: great deposits of natural resources, raw-material orientation of eonomy, limited economic possibilities of environment preservation etc. Almost total absence of scientifically reasoned state system of natural resources management is characteristic for our country, which necessitates research in this sphere. The analysis of environmental management problems was carried out on the basis of the Cobb-Douglas function. An approach to environmental management on the basis of natural objects' complexity has been proposed.

\section{REFERENCES}

[1] N.I Arkhipova, Industrial policy of Russia: global challenges, risks and national priorities/ N.I Arkhipova, I.M. Pomortseva, S.V. Shkodinskiy // Moscow State Regional University Press, Series: Economy. 2015, No. 2, pp. 28-34.

[2] N.I. Arkhipova, Changes of the role of factors as sources of competitiveness in modern world/ Arkhipova N.I., Rodionov I.I.// RGGU Press. Series: Economy. Management. Law.2015, No. 1, pp. 9-16.

[3] V. N. Nezamaikin, Theoretical-methodological provisions of natural - economic complexes management of the regions of RF: thesis : 08.00.05 / Nezamaikin Valeriy Nikolaevich; M., 2007. 405 p.

[4] V. A. Umnov, Economic reasoning of rational usage of subterranean space: thesis : 11.00.11 / Umnov Vitaliy Anatolievich; M., 2000. 213 p.

[5] I.M. Potravniy, D.V. Novikov, Ecological-landscape management of natural resources use. M., Economy - 2016, 254 p. 